was the first in the country to have a Certification in Internal Medical Service of companies.

\section{MUSCULOSKELETAL DISORDERS (MSD) AMONGST FARMERS IN THE KOURIFATE MUNICIPALITY, PROVINCE OF FQUIH BEN SALAH}

M Omar, I El Amri Benali, M Zouhair, A El Kholti. Casablanca Faculty of Medicine and Pharmacy, Hassan II University, Morocco

10.1136/oemed-2018-ICOHabstracts.490

Introduction MSD are one of the most worrying problems in occupational medicine, it affects workers in all business sectors. They group together a set of periarticular diseases, affecting the soft tissues of upper limbs, lower limbs and the back.

In Morocco, the agricultural sector plays an important role in economical, cultural and political life, it is an important source of employment. However, MSD represent a big problem in agriculture, most of the time, workers in this sector are exposed to uncomfortable positions, repetitive movements and carry heavy loads.

Methods This is a descriptive study of 52 cases of MSD among farmers who visits the Kourifate Health Centre. The study consists of interviewing each patient and completing a questionnaire.

Results This study allowed us to highlight the magnitude of the complaints concerning MSD problems amongst farmers and showed us the severity of the problem. Complaints about relatively severe MSD (in frequency, duration and severity) are more seen in lower back (77\%) shoulder joint (38.4\%), cervical spine $(32.6 \%)$ and finally in elbow and wrist joints (25\%).

Discussion Our study shows that there is a significant backlog in occupational health and safety in the agricultural sector, which mainly is an informal sector, and therefore there is a great need for assessment and prevention of occupational risks. Although our study is rich in information, we can't extrapolate our results to the whole sector given the size of our sample.

Conclusion Many farmers are aware of the need for medical follow-up and suffer from chronic pain requiring multidisciplinary care, but the lack of resources and the laxity in the enforcement of safety and health legislation are prolonging their suffering.

\section{WORKER HEALTH SURVEILLANCE: CHALLENGES TO MAKE IT HAPPEN}

${ }^{1}$ VA Mininel ${ }^{*},{ }^{2}$ MF da Silva, ${ }^{3}$ JA Camarotto, ${ }^{4}$ MABC Takahashi. ${ }^{1}$ Assistance Professor, Federal University of Sao Carlos, Sao Carlos, Brazil; ${ }^{2}$ Master's student, Federal University of Sao Carlos, Sao Carlos, Brazil; ${ }^{3}$ Full Professor, Federal University of Sao Carlos, Sao Carlos, Brazil, ${ }^{4}$ Researcher, Public Health School, University of Sao Paulo

\subsection{6/oemed-2018-ICOHabstracts.491}

Introduction Worker Health Surveillance is a continuous and systematic process of gathering, analysis and dissemination of data on work-related events, focused on planning and implementation of measures to health promotion, prevention of risks, diseases and harms and also professional rehabilitation. Requires integration of actions and services from healthcare system to ensure comprehensive healthcare workers. Thus, this study aimed to analyse the implementation of worker health surveillance actions in Sao Carlos, Brazil.
Methods qualitative study, performed in two steps:

1. analysis of documents and policies related to health care workers,

2. semi-structured interviews with managers and policy makers that works in health care system and has (or should have)

interface with health care worker surveillance.

Data collected were analysing through thematic analysis. This study was approved by research ethical committee and all ethical issues were respected.

Results Analysis of documents and policies show the existence of a National Comprehensive Workers Health Care (Renast), which proposes the articulation of healthcare actions and sectors, in the federal, state and regional levels. Such actions should be developed in the healthcare network, guided by Nacional Policy of Workers Health. Although national policies are well structured and defined, its implementation still meets barriers and challenges, mainly at the local level. Health managers and policy makers also suffer with this reality, showing difficulties to understand their role in the health network and to comprehend the worker health surveillance as a whole.

Discussion The health care services cannot implement worker health surveillance due disarticulation among governmental agencies, actions and professionals involved in the health network. As a result, we can see the invisibility of worker health surveillance in the health system, area that still remains treated as a specialty of occupational health/medicine, in a fragmented and disconnected way.

\section{EXERCISE PROTOCOL FOR WORK-RELATED MUSCULOSKELETAL DISORDERS}

1,2Suparna Damany. 'Damany Centre For Chronic Pain And Holistic Well-being, Allentown, USA; ${ }^{2}$ Adjunct professor, DeSales University, Bethlehem, Pennsylvania, USA

\subsection{6/oemed-2018-ICOHabstracts.492}

Work-related musculoskeletal disorders are easily mitigated and prevented by a specific exercise program that targets the various bodily systems involved in the condition.

A telemedicine program will be discussed with a discussion of five (out of a sample of 200) cases with work-related musculoskeletal injuries. They were advised to follow a program based on the pathophysiology of these condition, and their symptom complex. A general protocol to target computerrelated musculoskeletal symptoms has been developed through the successful treatment of these sufferers.

A discussion of the differences in this protocol and the traditional care will follow.

\section{SCIENTIFIC EVIDENCE OF OCCUPATIONAL EXPOSURE TO ORGANIC SOLVENTS AND ITS RELATIONSHIP WITH HEARING LOSS}

Juan Ignacio Rincón Sarmiento*. Independent Practitioner

10.1136/oemed-2018-ICOHabstracts.493

A systematic review was carried out about the auditory effect of occupational exposure to solvents. For such purpose, four data bases, chosen on the bases of their methodological quality and level of specialisation in this domain, were 
comprehensively explored. The criteria for inclusion and exclusion of articles were carefully selected, and they were analysed and evaluated according to the way in which they gave an answer to each of the questions posited.

This information was consolidated in a table in which each article was assessed according to the way it responded to each question. In this way, it was possible to draw conclusions and propose specific recommendations about every aspect related to the phenomenon studied.

As a conclusion, it is stated that occupational exposure to organic solvents, particularly the aromatic ones, has harmful effects in the auditory apparatus. Additionally, it was found such exposure enhances the auditory effect generated by noise in a synergic manner. This was particularly evident in the case of workers exposed to noise for more than 3 years, being particularly harmful high auditory frequencies $(4 \mathrm{KHz}$ a $8 \mathrm{KHz}$ ). Among the solvents which relate to such effect more strongly, it is possible to mention: Toluene, Styrene and Xylene (in this order).

\section{HEALTH SERVICES IN THE SOUTH AFRICAN MINING INDUSTRY}

TM Balfour. Chamber of Mines of South Africa

\subsection{6/oemed-2018-ICOHabstracts.494}

Introduction South African mining companies have historically provided health services to their employees. The standard managed care or capitation delivery method is not the only one available as employees are shifting to medical aid. South Africa has adopted the National Health Insurance (NHI) Policy and mine health facilities will be part of an NHI system. The Chamber of Mines conducts three yearly surveys of its members focusing on how health services are provided and such a survey was conducted in 2015.

Methods Primary data was collected during October 2015, using structured questionnaires sent to all Chamber members. Responses were then collated and analysed on Excel.

Results Thirty-three (33) mines, which make up $47.8 \%$ of Chamber members, representing 331262 employees or $74 \%$ of the employees in the industry, responded to the survey. Overall, occupational Health Services were available to all $(100 \%)$ contractors and permanent employees. Emergency Care Services were provided to all except 2.8\% (2304) of contractors. Primary Health Care Services were available to $97.4 \%$ of permanent employees and $54.5 \%$ of contractors. Hospital in-patient Care was available to $90.7 \%$ of permanent employees and $38.3 \%$ of contractors. Sixty-one percent (61\%) of employees were on medical aid. Overall, all mines provided TB screening and HIV counselling services.

Discussion Results showed that occupational and emergency services were well provided to all employees. Medical aid membership had increased over the years, with more employees going onto open medical aid schemes.

Conclusion There have been shifts in how health services are rendered by mining companies in South Africa. These shifts have to be taken into account when companies and the country are planning for delivery of future health services, particularly for the NHI.
161 THE 'CHANGE LABORATORY' AS A METHOD PROVIDING AN ELEMENTARY SCHOOL FORMATIVE INTERVENTION: A NEW PERSPECTIVE IN OCCUPATIONAL HEALTH

Ella Triumpho Avellar, Frida Marina Fischer*. Department of Environmental Health, School of Public Health, Universidade de São Paulo, São Paulo, Brazil

\subsection{6/oemed-2018-ICOHabstracts.495}

Introduction A management team of a municipal secretary of education had a great concern about the great number of sick leave episodes of their teachers. Sessions aiming a school formative intervention showed the initial demand changed and turned to be the stress at work and its consequences which were perceived by the teachers.

Methods We used the 'Change Laboratory' (CL) method to evaluate work conditions, consequences and possible interventions. This method comprises of a set of tools for collaborative learning through experimentation at the workplace, carrying out changes in organisational practices. During 30 sessions, which took place once a week from 08/2015 to 09/ 2016, participated the elementary public-school teachers, the school management team, safety and occupational health technicians and representatives of human resources department. Individual interviews and meetings were also conducted with all participants.

Results Teachers created a new teaching work model with their daily activities in a comprehensive and collective way. They identified manifestations of tiredness and exhaustion like physical and mental fatigue ('waking up already feeling tired', voice disorders, lack of time and willingness to join social and leisure activities). Some of the causes of short term sickness absences were related to the needs to take care of personal and family life. The method allowed the safety service technicians to obtain detailed information of teachers' work activities and occupational health aspects.

Discussion The CL method provided to the teachers the opportunity to develop leadership and empowerment, such as the discussion of proposals to improve their daily work, relationships with students' families and with the management school team. Being closer to the reality of how work activities were performed by the teachers, the team of occupational health professional's experienced new ways of working to improve the organisation and workplace and eventually teachers' health. Financial support: FAPESP.

\section{DATA OF OCCUPATIONAL-MEDICAL CHECK-UP EXAMINATIONS CHALLENGING THE CONCEPT OF ALLOSTATIC LOAD}

${ }^{1} \mathrm{~A}$ Esser, ${ }^{1} \mathrm{~T}$ Kraus, ${ }^{2} \mathrm{H}$ Minten, ${ }^{2} \mathrm{~A}$ Tautz, ${ }^{1} \mathrm{~J}$ Lang. ${ }^{1}$ Institute of Occupational and Social Medicine, Medical Faculty of RWTH Aachen University, Germany; ${ }^{2}$ Corporate Health Management - Germany, Deutsche Post DHL-Group, Bonn, Germany

\subsection{6/oemed-2018-ICOHabstracts.496}

Introduction The Allostatic Load Index (ALI) [McEwen 1993, 2001] assesses the physiological adaption to chronic stress by cumulative changes in the circulation, respiration, inflammation, metabolic and anthropometric system. The ALI thus can function as a risk marker for secondary prevention in occupational medicine. The aim of this study was to create an ALI 